\title{
תणुత] Übungen
}



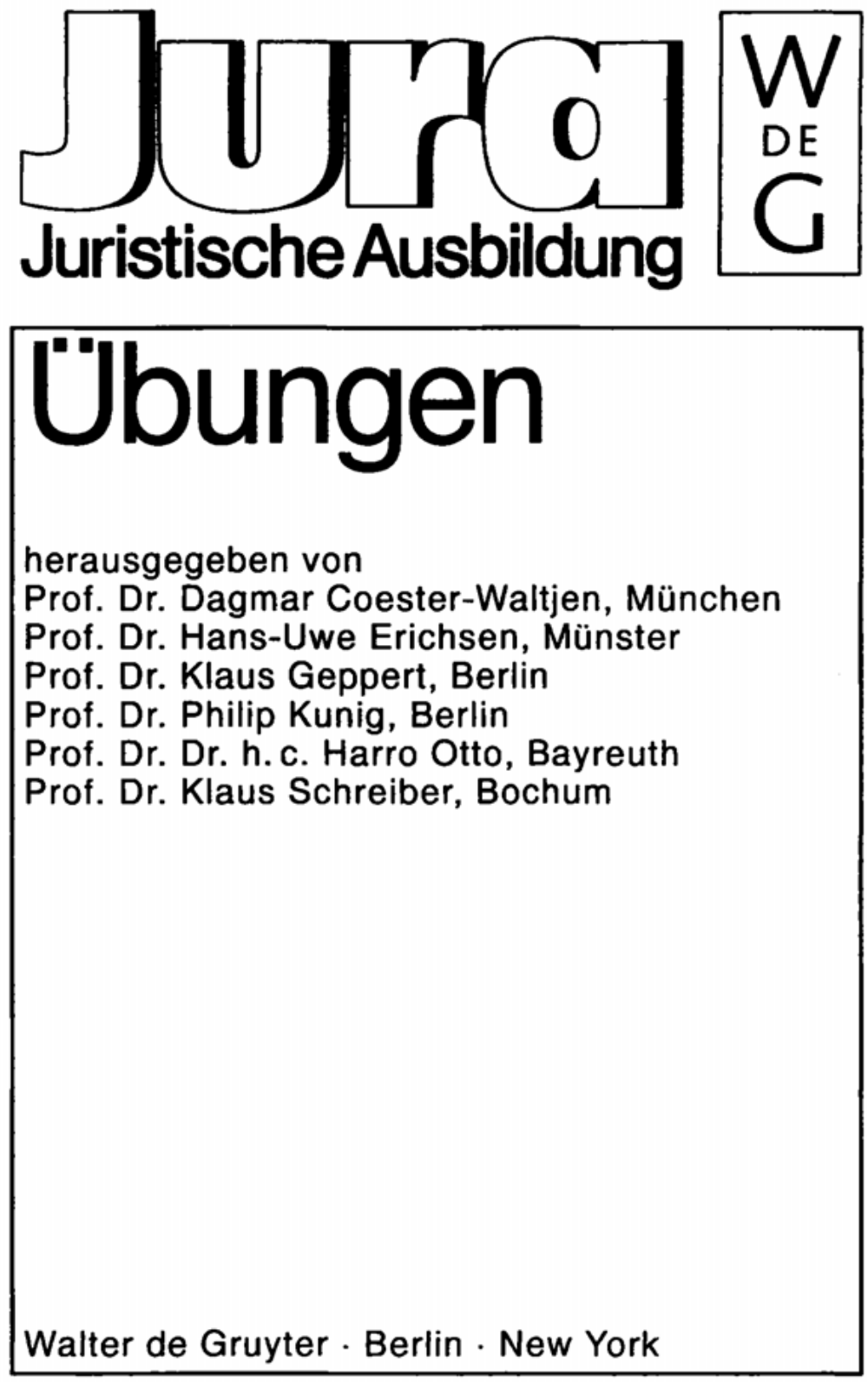


\section{Übungen in Internationalem Privatrecht und Rechtsvergleichung}

von

Dagmar Coester-Waltjen Gerald Mäsch

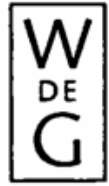

Walter de Gruyter - Berlin - New York · 1996 
Dr. iur. Dagmar Coester-Waltjen, LL.M. (University of Michigan), o. Professorin für Bürgerliches Recht, Zivilprozeßrecht, Internationales Privatrecht, Rechtsvergleichung. Vorstand des Instituts für Internationales Recht - Rechtsvergleichung - an der Universität München.

Dr. iur. Gerald Mäsch, Wissenschaftlicher Assistent am Institut für Internationales Recht Rechtsvergleichung - an der Universität München.

@ Gedruckt auf säurefreiem Papier, das die US-ANSI-Norm über Haltbarkeit erfüllt.

Die Deutsche Bibliothek - CIP-Einbeitsaufnabme

Coester-Waltjen, Dagmar:

Übungen in internationalem Privatrecht und Rechtsvergleichung / von Dagmar Coester-Waltjen ; Gerald Mäsch. - Berlin ; New York: de Gruyter, 1996

(Jura: Übungen)

ISBN 3-11-014734-3

NE: Mäsch, Gerald:

\section{() Copyright 1996 by Walter de Gruyter \& Co., D-10785 Berlin.}

Dieses Werk einschließlich aller seiner Teile ist urheberrechtlich geschützt. Jede Verwertung außerhalb der engen Grenzen des Urheberrechtsgesetzes ist ohne Zustimmung des Verlages unzulässig und strafbar. Das gilt insbesondere für Vervielfältigungen, Übersetzungen, Mikroverfilmungen und die Einspeicherung und Verarbeitung in elektronischen Systemen.

Printed in Germany

Datenkonvertierung: buslau intercom services, 12161 Berlin

Druck und Bindearbeiten: WB-Druck, 87669 Rieden am Forggensee 